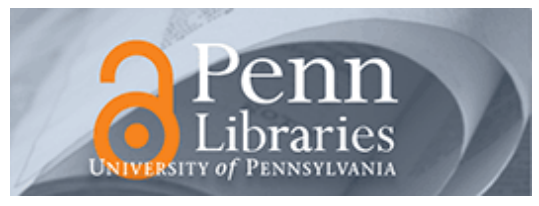

University of Pennsylvania

ScholarlyCommons

Management Papers

Wharton Faculty Research

$1-2012$

\title{
Policy Bundling to Overcome Loss Aversion: A Method for Improving Legislative Outcomes
}

\author{
Katherine L. Milkman \\ University of Pennsylvania \\ Mary Carol Mazza \\ Lisa L. Shu \\ Chia-Jung Tsay \\ Max H. Bazerman
}

Follow this and additional works at: https://repository.upenn.edu/mgmt_papers

Part of the Business Law, Public Responsibility, and Ethics Commons, Economics Commons, and the Organizational Behavior and Theory Commons

\section{Recommended Citation}

Milkman, K. L., Mazza, M., Shu, L. L., Tsay, C., \& Bazerman, M. H. (2012). Policy Bundling to Overcome Loss Aversion: A Method for Improving Legislative Outcomes. Organizational Behavior and Human Decision Processes, 117 (1), 158-167. http://dx.doi.org/10.1016/j.obhdp.2011.07.001

This paper is posted at ScholarlyCommons. https://repository.upenn.edu/mgmt_papers/147

For more information, please contact repository@pobox.upenn.edu. 


\title{
Policy Bundling to Overcome Loss Aversion: A Method for Improving Legislative Outcomes
}

\begin{abstract}
Policies that would create net benefits for society that contain salient costs frequently lack enough support for enactment because losses loom larger than gains. To address this consequence of loss aversion, we propose a policy-bundling technique in which related bills involving both losses and gains are combined to offset separate bills' costs while preserving their net benefits. We argue this method can transform unpopular individual pieces of legislation, which would lack the support for implementation, into more popular policies. Study 1 confirms that bundling increases support for bills with costs and benefits and that bundled legislation is valued more than the sum of its parts. Study 2 shows this finding stems from a diminished focus on losses and heightened focus on gains. Study 3 extends our findings to policies involving costs and benefits of the same type (e.g., lives) generated by different sources (e.g., food vs. fire safety).
\end{abstract}

\section{Keywords}

loss aversion, prospect theory, policy bundling, behavioral economics, joint-separate evaluation

\section{Disciplines}

Business Law, Public Responsibility, and Ethics | Economics | Organizational Behavior and Theory | Social and Behavioral Sciences 
H A R VAR D B U S I N E S S S S C H O O L

\section{Policy Bundling to Overcome Loss Aversion: A Method for Improving Legislative Outcomes}

Katherine L. Milkman

Mary Carol Mazza

Lisa L. Shu

Chia-Jung Tsay

Max H. Bazerman

\section{Working Paper}

09-147

Copyright ( 2009 by Katherine L. Milkman, Mary Carol Mazza, Lisa L. Shu, Chia-Jung Tsay, and Max H. Bazerman

Working papers are in draft form. This working paper is distributed for purposes of comment and discussion only. It may not be reproduced without permission of the copyright holder. Copies of working papers are available from the author. 


\title{
Policy Bundling to Overcome Loss Aversion:
}

\section{A Method for Improving Legislative Outcomes}

\author{
Katherine L. Milkman \\ The University of Pennsylvania, Philadelphia, PA 19104 \\ $\begin{array}{cc}\text { Mary Carol Mazza } & \text { Lisa L. Shu } \\ \text { Chia-Jung Tsay } & \text { Max H. Bazerman }\end{array}$ \\ Harvard University, Cambridge, MA 02138
}

Wordcount: 2,495 


\begin{abstract}
Policies that would create net benefits for society but would also involve costs frequently lack the necessary support to be enacted because losses loom larger than gains psychologically. To reduce the harmful consequence of loss aversion, we propose a new type of policy bundling technique in which related bills that have both costs and benefits are combined. In our first laboratory study, we confirm across a set of four legislative domains that this bundling technique increases support for bills that have both costs and benefits. We also show in a second study that this effect stems from a diminished focus on losses and heightened focus on gains when policies are evaluated in bundled form.
\end{abstract}

Keywords: loss aversion; policy bundling; behavioral economics 


\section{Introduction}

Citizens hope their elected representatives will pass legislation that creates net gains that outweigh net harms-legislation that has positive expected value for society. However, Nobel Laureate Joseph Stiglitz (1998) has noted that legislators often fail to pass such legislation, even when the net positive expected value is highly significant. Social scientists have pointed to the dysfunctional role of special interest groups in contorting our political processes and contributing to sub-optimal outcomes (Baron, 1998), and several cognitive explanations for the failure to pass legislation with positive expected value have also been discussed (Baron, Bazerman, \& Shonk, 2006; Ritov \& Baron, 2009). This paper highlights one cognitive barrier to passing legislation with positive expected value for society and proposes a solution.

The psychology and economics literature suggests that legislators face an uphill battle when proposing legislation that has both costs and benefits due to the power of loss aversion, a cognitive bias that causes individuals to dramatically overweight losses relative to gains (Kahneman \& Tversky, 1979; Tversky \& Kahneman, 1992). Because losses loom larger than gains psychologically, policies that would create net benefits for society but would also involve

costs may frequently be defeated. Policymakers would thus benefit from learning how to combat loss aversion and reduce its impact on the perception of legislation with both costs and benefits. To achieve this, we propose a specialized type of policy bundling.

Legislators frequently combine unrelated policies supported by different groups into a single bill to increase support for their legislation. For example, conservatives might add a consumer protection law to their proposed budget to garner liberal support. We propose a different type of bundling technique: one in which related bills are combined in a way that reduces the harmful effects of the tendency to irrationally overweight losses relative to gains. 
Our proposed policy bundling method combines one bill that has costs in Domain A (e.g., job losses in Town X) and benefits in Domain B (e.g., acres of forest preserved in Town X) with a matched bill that has the inverse structure: benefits in Domain A (e.g., job gains in Town Y) and costs in Domain B (e.g., acres of forest lost in Town Y). Within each domain, costs of a specific type (e.g., job losses in Town $\mathrm{X}$ ) in one bill must be offset by greater benefits of the same type (e.g., job gains in Town Y) in the second bill (see Table 1).

When such bills are evaluated independently, we hypothesize that losses will be comparatively more salient, and people’s aversion to losses will drive high rates of opposition. Even if precisely the same information is presented in a bundled piece of legislation as in two independent bills, because losses cancel out in the combined bill (by design), gains will be comparatively more salient, and loss aversion will exert less influence. Thus, when a bundled bill is evaluated, we predict it will achieve considerably greater support than either of its component bills and will in fact be valued more than the sum of its parts.

\section{Study 1}

\section{Method}

168 participants were recruited to participate in an hour-long set of studies in a computer lab on a large university campus in the Northeastern United States in exchange for \$15. Participants completed our study at computer terminals and then participated in two other unrelated studies.

During our study, participants were presented with four different hypothetical pieces of legislation, each with a different cost-versus-benefit tradeoff. For example, one cost-benefit tradeoff involved cutting jobs but gaining acres of protected forest in a hypothetical community while the matched bill involved a gain of jobs but a loss of acres. Each piece of legislation was 
either a single bill pertaining to an individual policy with costs and benefits or a combined bill where the costs and benefits of two separate bills summed to generate net benefits in two domains. For the tradeoff highlighted above, participants were randomly assigned to view one of the following three bills:

- Bill 1: A law to establish new park areas in Community X where logging would be prohibited, costing the community 100 jobs but preserving 60,000 acres of forest;

- Bill 2: A law to eliminate a protected park area in Community Y, which would allow logging on 50,000 acres of previously protected forest, destroying that forest region but creating 125 new jobs;

- Combined Bill: A bundled bill presenting the proposals in both Bill 1 and Bill 2 above, together as two components of a single piece of legislation.

The three other types of tradeoffs studied included (see Table 2):

(1) A tradeoff between reduced/(increased) hours of gridlock and more/(fewer) fender benders due to the absence/(presence) of a traffic light at a dangerous intersection.

(2) A tradeoff between more/(fewer) hours of scheduled brownouts and fewer/(more) pollution-related health complaints due to fewer/(more) power plants.

(3) A tradeoff between an increase/(reduction) in a city's capacity for children in its playgrounds and an increase/(decrease) in the number of disease-carrying rodents in the city attracted by the increased/(decreased) presence of playground spaces. ${ }^{1}$

After viewing the details of a given policy (see online supplement for study materials), participants were asked if they would vote for or against the bill in question. Participants who had voted for/(against) a bill were then asked how many hours they would want their legislator to 
devote to supporting/(opposing) the passage of the bill - a measure of the strength of their support for the legislation. Strength of support is tabulated as the number of hours a participant would want his or her legislator to spend supporting a bill’s passage, with hours spent in opposition taking on negative values. In other words, if one participant voted for a bill and indicated she would want her legislator to spend 3 hours supporting its passage, her strength of support in hours would be classified as 3. If another participant voted against the bill and indicated she would want her legislator to spend 2 hours opposing its passage, her strength of support in hours would be classified as -2. This strength of support measure captures precisely how much an individual values a given outcome, following the traditional economic measure of "willingness to pay."

\section{Results and Discussion}

As illustrated in Table 2, in each of the four policy domains studied, we find that support for a combined bill is significantly greater than support for either of its separate, component bills. For example, for the jobs/forestry policies described above, 83\% of participants indicated they would vote for the Combined Bill, a significantly greater show of support than that achieved independently by either Bill 1 (54\%; $p<0.01)$ or Bill 2 (45\%; $p<0.01)$. These findings substantiate our contention that policy bundling may be an effective tool for policymakers hoping to pass legislation that is advantageous overall, but that contains obvious and unavoidable costs.

Further, by measuring the strength of support for each bill, we are able to determine whether this finding could be explained by voters favoring one policy in a bundle more strongly than they oppose the other, and thus voting to pass a joint bill when they would not support one of its component bills. If such compromise were responsible for our findings, strength of support 
in legislator hours for each combined bill should equal the net strength of support in hours for its component bills. We show, however, in every one of the four policy domains studied that policy bundling is not effective due to compromise. The average number of hours a participant would want his or her legislator to devote to supporting two separate bills sums to significantly fewer hours than the average number of hours a participant would want his or her legislator to devote to supporting the combined bill (see Table 2). ${ }^{2}$ For example, for the jobs/forestry policies described above, participants reported that, on average, they would want their legislator to spend a total of 24 hours working to support the passage of the Combined Bill - significantly more time, on average, than participants reported they would want their legislator to spend, in total, working to support Bill 1 (1 hour) and Bill 2 (-31 hours) (see Table 2). ${ }^{3}$ We therefore conclude that our results are due to a psychological difference between the way people evaluate individual bills with salient costs versus the way they evaluate combined legislation where the costs embedded in individual bills are overshadowed by their net benefits.

\section{Study 2}

While the hypotheses tested and supported by Study 1 stem from previous research on loss aversion, Study 1's design does not allow us to evaluate the mechanism leading to increased support for bundled policies. To determine whether, as predicted, a reduction in the salience of losses in bundled legislation is responsible for the higher levels of support we observe for bundled policies relative to their component policies, we conducted a second study. In Study 2, we investigated the reasoning that led people to support or oppose different pieces of legislation.

\section{Method}

314 participants were recruited to participate in an hour-long set of studies in a computer lab on a large university campus in the Mid-Atlantic region of the United States in exchange for 
\$10. Participants completed our study at computer terminals and then participated in a series of other unrelated studies.

Each participant was presented with a single, hypothetical piece of legislation. Participants were randomly assigned to view one of three versions of the legislation from Study 1 involving a tradeoff between jobs and acres of protected forest (see online supplement): (1) Bill 1, which involved job losses and acreage gains ( $\mathrm{N}=124)$, (2) Bill 2, which involved job gains and acreage losses $(\mathrm{N}=115)$, or (3) Combined Bill, which presented Bills 1 and 2 together as a single piece of legislation ( $\mathrm{N}=75)$. Participants were first asked if they supported the bill in question. Then they were asked to "write a paragraph describing [their] thought process as [they] approached the decision and the reasons [they] came to [their] conclusion.”

\section{Results and Discussion}

As in Study 1, we find that support for a combined bill is significantly greater than support for either of its separate, component bills. 87\% of participants indicated they would vote for the Combined Bill, a significantly greater show of support than that achieved independently by either Bill 1 (56\%; $p<0.01)$ or Bill $2(45 \%$; $p<0.01)$.

Two research assistants who were blind to our hypotheses and experimental conditions were trained to code participants' reported thought processes. Coders were asked to answer two questions: (1) Does the free response make any mention of losses/costs (or any synonym) (y/n)? and (2) Does the free response make any mention of benefits/gains (or any synonym) (y/n)? An agreement rate of 75\% (kappa $=0.51, \mathrm{p}<0.01)$ was achieved for coding losses/costs, and an agreement rate of 72\% $(\mathrm{kappa}=0.45, \mathrm{p}<0.01)$ was achieved for coding benefits/gains. Thoughts of losses/(gains) were coded as present (code $=1$ ) or absent (code $=0$ ) when both coders agreed, and in cases of disagreement, the codes were averaged (code $=0.5$ ). 
As predicted, we found that significantly fewer participants were coded as thinking about losses when evaluating the Combined Bill (31\%) than when evaluating Bill 1 (66\%; $\mathrm{p}<0.01)$ or Bill 2 (56\%; $\mathrm{p}<0.01)$. In addition, significantly more participants were coded as thinking about gains when evaluating the Combined Bill (86\%) than when evaluating Bill 1 (44\%; $\mathrm{p}<0.01)$ or Bill 2 (62\%; $\mathrm{p}<0.01)$. These results support our prediction that policy bundling reduces the salience of losses in legislation’s component parts and heightens the salience of gains.

\section{General Discussion}

We believe the policy bundling method discussed above has the potential to help citizens and legislators pass legislation with net benefits but salient costs. Single pieces of legislation often fail to gain the necessary support for enactment because they are narrowly bracketed, and thus legislators are unable to overcome loss aversion. We hope that the bundling method proposed in this paper may help legislators move beyond the irrational reluctance to support wise legislation that loss aversion can induce.

Previous research highlighting policy applications of loss aversion has proven extremely valuable. A knowledge of people's tendency to view any deviation from the status quo as an aversive loss (Samuelson \& Zeckhauser, 1988) has helped policymakers understand the enormous implications of defaults on important issues such as organ donation (Johnson \& Goldstein, 2004) and 401k participation (Madrian \& Shea, 2001). We believe that knowledge of a strategy for overcoming loss aversion through bundling could similarly help policymakers pass better legislation.

While the behavioral decision research literature has shown the difficulty of fully debiasing human judgment (see Milkman, Chugh \& Bazerman, 2009 for a review), we can design decision-making contexts in ways that lead to wiser choices (Thaler \& Sunstein, 2008). 
By using our bundling strategy, policymakers may be better able to overcome the pitfalls of loss aversion and, in turn, affect more positive legislative change. 


\section{References}

Baron, J. (1998). Judgment misguided: Intuition and error in public decision making. New York, NY: Oxford University Press.

Baron, J., Bazerman, M.H., \& Shonk, K. (2006). Enlarging the societal pie through wise legislation: A psychological perspective. Perspectives on Psychological Science, 1, 123-132.

Johnson, E. J., \& Goldstein, D. G. (2004). Defaults and donation decisions. Transplantation, 78, 1713-1716.

Kahneman, D. \& Tversky, A. (1979). Prospect theory: An analysis of decision under risk. Econometrica, 47, 263-291.

Madrian, B. \& Shea, D.F. (2001). The power of suggestion: Inertia in 401(k) participation and savings behavior. Quarterly Journal of Economics, 116, 1149-1187.

Milkman, K.L., Chugh, D., \& Bazerman, M.H., (2009). How can decision making be improved? Perspectives on Psychological Science, 4, 379-383.

Ritov, I., \& Baron, J. (2009). Joint presentation reduces the effect of emotion on evaluation of public actions. Unpublished working paper.

Samuelson, W. \& Zeckhauser, R. (1988). Status quo bias in decision making. Journal of Risk and Uncertainty, 1, 7-59.

Stiglitz, J. (1998). The private uses of public interests: Incentives and institutions. Journal of Economic Perspectives, 12, 3-22.

Thaler, R., \& Sunstein, C. (2008). Nudge: Improving decisions about health, wealth and happiness. New Haven, CT: Yale University Press.

Tversky, A., \& Kahneman, D. (1992). Advances in prospect theory: cumulative representation of uncertainty. Journal of Risk and Uncertainty, 5, 297-323.

Acknowledgements

We thank Katie Shonk for her excellent editorial assistance and Ronnie Wang and Benjamin Lopez for their help with coding. 


\section{Tables}

\begin{tabular}{|c|c|c|}
\hline \multicolumn{3}{|c|}{$\begin{array}{l}\text { Table } 1 \\
\text { Illustration of new policy bundling concept, where } n \text {, } \\
m>0 \text {. }\end{array}$} \\
\hline & Domain A & Domain B \\
\hline Bill 1 & Costs of Size X & Benefits of Size Y \\
\hline Bill 2 & Benefits of Size $X+n$ & Costs of Size Y - m \\
\hline
\end{tabular}

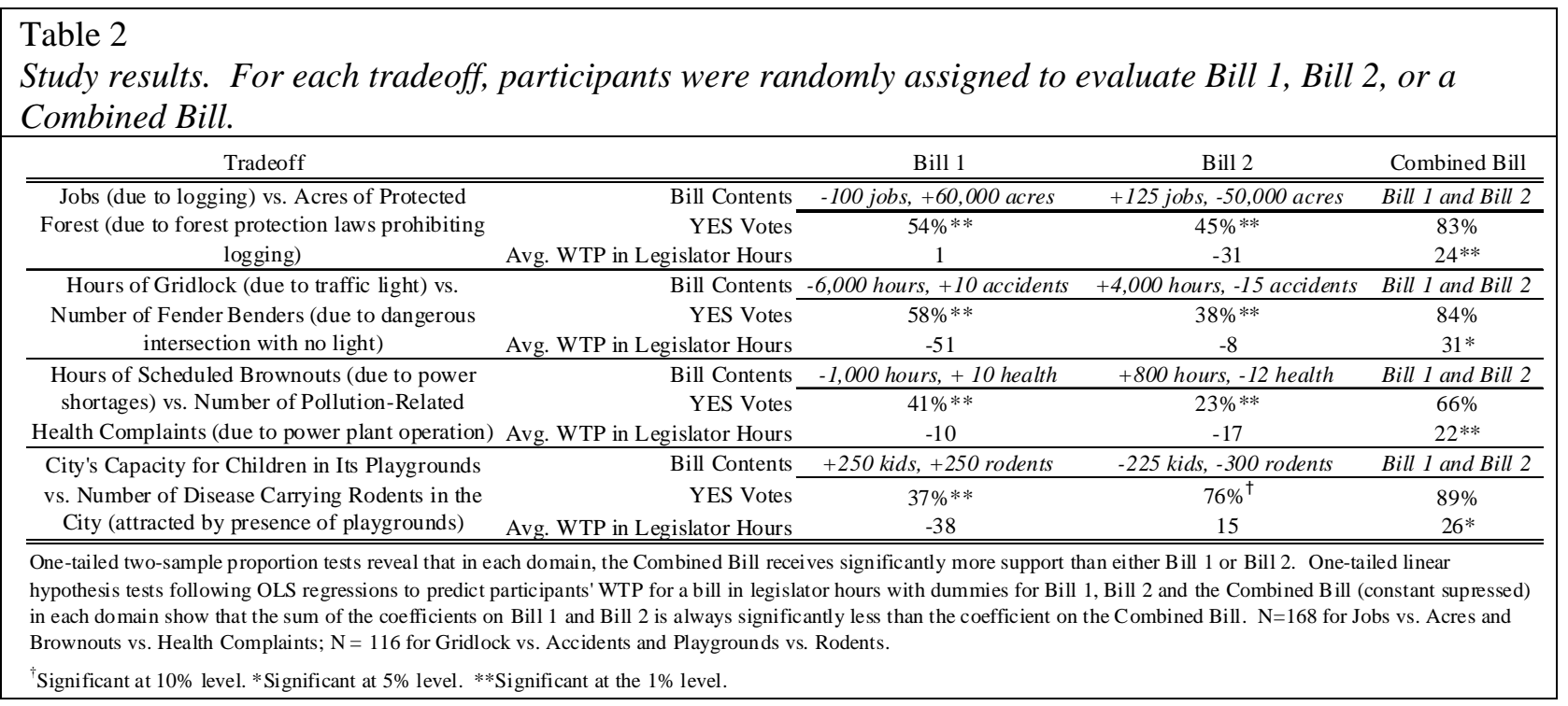


Appendix

Questions Asked of Participants about Each Bill after They Read Its Contents

- Do you support this bill?

_ YES — NO

\section{[PAGE BREAK]}

- How many dollars would you be willing to donate to support ${ }^{4}$ the passage of this bill?: dollars

- How many hours would you be willing to spend making phone calls to support ${ }^{4}$ the passage of this bill?: hours

- How many miles would you be willing to walk in a walkathon to support ${ }^{4}$ the passage of this bill?: miles

- If you were a member of community X, how many hours of his/her time would you want your local representative to devote to supporting ${ }^{4}$ the passage of this bill?:

hours 


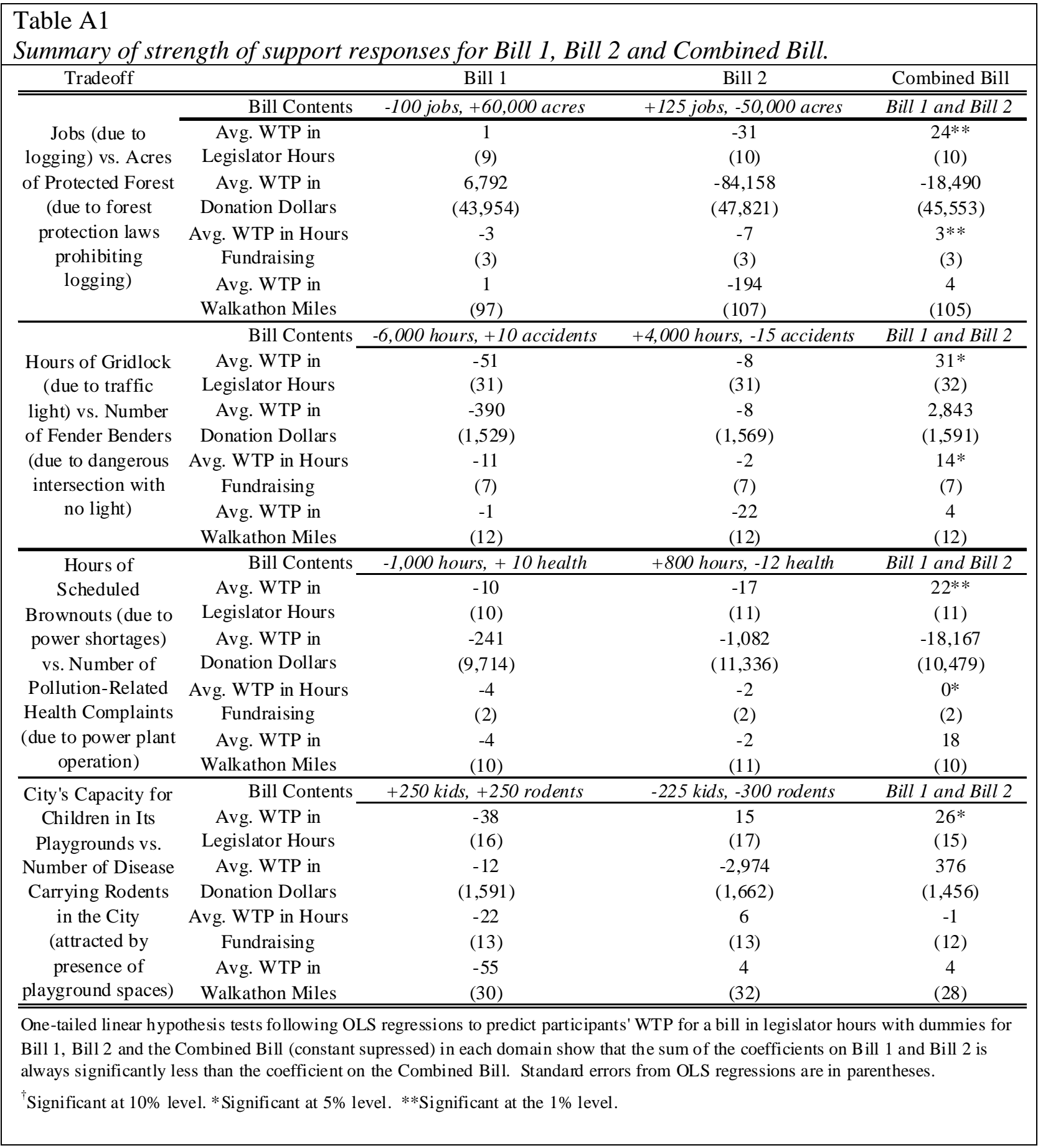




\section{Footnotes}

1 Only 116 participants responded to tradeoffs involving gridlock vs. fender benders and playground capacity vs. rodents.

2 For all tradeoffs, one-tailed linear hypothesis tests conducted following regressions to predict participants' strength of support for a bill in legislator hours with dummies for Bill 1, Bill 2, and the Combined Bill (constant suppressed) show that the sum of the coefficients on Bill 1 and Bill 2 is significantly less than the coefficient on the Combined Bill.

3 Three other measures of strength of support for each bill were also collected, each involving a participant's willingness to commit his/her own resources to supporting or opposing a given piece of legislation (hours, dollars, or miles walked). These additional measures exhibit patterns similar to those presented in Table 2 pertaining to hours a participant would want his/her legislator to spend supporting or opposing a bill's passage, although nearly half of participants were unwilling to commit any of their own resources to supporting or opposing legislation, leading to a reduction in the sensitivity of these three measures (due to high variance in strength of support responses). Appendix Table A1 presents detailed statistics for all strength of support data collected.

4 If participant selected “yes” in response to the question - "Do you support this bill?", this read "support.” Otherwise, this read “oppose”. 


\section{Supporting Online Materials}

The wording of each bill presented to participants for each of the four tradeoffs studied:

\section{Tradeoff 1}

About Community X:

Community $\mathrm{X}$ is situated in the middle of the National Forest.

Community $\mathrm{X}$ has high overall unemployment.

Community X employs many individuals in the foresting industry.

The average yearly wage of loggers in community $\mathrm{X}$ is $\$ 41,000$.

About the National Forest:

The National Forest encompasses 1,000,000 acres.

One square mile is equal to 640 acres.

600,000 acres of the National Forest are currently leased to logging firms.

[Bills 1 and 2]

This Bill:

Within the eastern part of the National Forest, there is a [B1: 60,000]/[B2: 50,000] acre parcel of land that has been logged over the last 125 years and is currently [B1: leased to a private timber firm. The lease]/[B2: protected from logging. The land's protected status] expires this year. This bill would not renew the $[B 1$ : lease]/[B2: protected status], and would [B1: protect the parcel of land from further harvesting]/[B2: permit leasing of this parcel of land for logging]. This would result in the [B1: loss of 100]/[B2: creation of 125] jobs for the foreseeable future in Community X.

\begin{tabular}{|l|l|}
\hline Change in Community X Jobs & Change in Protected Acres \\
\hline [B1: 100 Jobs LOST]/ & {$[B 1: 60,000$ Acres GAINED]/ } \\
[B2: 125 Jobs Gained $]$ & {$[B 2: 50,000$ Acres LOST] } \\
\hline
\end{tabular}

[Combined Bill]

This bill has two parts:

PART A. [Text of Bill 1 from above].

PART B. [Text of Bill 2 from above].

\begin{tabular}{|l|l|l|}
\hline Bill & Change in Community X Jobs & Change in Protected Acres \\
\hline A & 100 Jobs LOST & 60,000 Acres GAINED \\
\hline B & 125 Jobs GAINED & 50,000 Acres LOST \\
\hline
\end{tabular}




\section{Tradeoff 2}

About the State Highway:

One 5-mile stretch of the State Highway near downtown is known for its frequent accidents, with an average of 100 fender-benders per year.

Traffic lights on highways reduce the number of fender-benders, but increase the amount of time commuters must spend to travel the same distance.

\section{[Bills 1 and 2]}

The State Legislature is considering the following bill.

This bill would [B1: remove]/[B2: add] a traffic light [B1: from]/[B2: to] a specific section of the 5-mile stretch of State Highway. This would [B1: reduce]/[B2: increase] the total amount of time spent on the 5mile stretch by all drivers combined over the course of a year by a total of $[B 1: 6,000] /[B 2: 4,000]$ hours. However, it would result in [B1: 10 more]/[B2: 15 fewer] fender-benders per year on the State Highway.

\begin{tabular}{|l|l|}
\hline Change in Gridlock hours & Change in Fender-Benders \\
\hline$[B 1: 6,000$ Hours LESS TRAFFIC $]$ & {$[B 1: 10$ MORE } \\
{$[B 2: 4,000$ Hours MORE TRAFFIC $]$} & {$[B 2: 15$ FEWER $]$} \\
\hline
\end{tabular}

[Combined Bill]

The State Legislature is considering the following bill. This bill has two parts:

PART A. [Text of Bill 1 from above].

PART B. [Text of Bill 2 from above].

\begin{tabular}{|l|l|l|}
\hline Bill & Change in Gridlock hours & Change in Fender-Benders \\
\hline A & 6,000 Hours LESS TRAFFIC & 10 MORE \\
\hline B & 4,000 Hours MORE TRAFFIC & 15 FEWER \\
\hline
\end{tabular}




\section{Tradeoff 3}

About State X:

State $\mathrm{X}$ is a suburban community in the United States.

State X has energy plants that generate enough power to meet the energy needs of its residents and businesses, with occasional shortages. When shortages arise, the power companies announce pre-planned blackouts. During these pre-planned blackouts, electricity is shut off for a pre-scheduled period of time in pre-determined areas.

The State Legislature is considering the following bill:

[Bill 1]

This bill would lead to the construction of a new energy plant in Town A within State X. This will reduce power shortages and reduce the number of pre-planned blackouts. The new energy plant will reduce the number of blackout hours in Town A by 1,000 hours every year. However, the new plant will increase the amount of pollution in Town A. It is expected that 10 more pollution-related health complaints will be filed annually as a result of the construction of a new plant.

\begin{tabular}{|l|l|}
\hline $\begin{array}{l}\text { Change in Total Hours of } \\
\text { Pre-planned Blackouts }\end{array}$ & $\begin{array}{l}\text { Change in Pollution-Related } \\
\text { Health Complaints }\end{array}$ \\
\hline 1,000 FEWER Hours & 10 MORE Filed Complaints \\
\hline
\end{tabular}

[Bill 2]

This bill would lead to the closure of one of the existing energy plants in Town B within State X. This will reduce the amount of pollution in Town $\mathrm{B}$, and it is expected that 12 fewer pollution-related health complaints will be filed annually. However, shutting down an energy plant will increase the number of pre-planned blackouts. This will result in an expected increase of 800 more hours of pre-planned blackouts every year.

\begin{tabular}{|l|l|}
\hline $\begin{array}{l}\text { Change in Total Hours of } \\
\text { Pre-planned Blackouts }\end{array}$ & $\begin{array}{l}\text { Change in Pollution-Related } \\
\text { Health Complaints }\end{array}$ \\
\hline 800 MORE Hours & 12 MORE Filed Complaints \\
\hline
\end{tabular}

\section{[Combined Bill]}

The State Legislature is considering the following bill. This bill has two parts:

PART A. [Text of Bill 1 from above].

PART B. [Text of Bill 2 from above].

\begin{tabular}{|l|l|l|}
\hline Bill & $\begin{array}{l}\text { Change in Total Hours of } \\
\text { Pre-planned Blackouts }\end{array}$ & $\begin{array}{l}\text { Change in Pollution-Related } \\
\text { Health Complaints }\end{array}$ \\
\hline A & 1,000 FEWER Hours & 10 MORE Filed Complaints \\
\hline B & 800 MORE Hours & 12 MORE Filed Complaints \\
\hline
\end{tabular}




\section{Tradeoff 4}

About City Y:

City Y is a densely populated metropolitan community in the United States

\section{[Bills 1 and 2]}

The Municipal Legislature is considering the following bill:

This bill proposes renovating the current downtown by [B1: adding a new]/[B2: removing an existing] playground with the capacity for [B1: 250]/[B2: 225] children. [B1: However,] it has been carefully determined that [B1: building a new playground in the designated area]/[B2: removing this particular playground] is likely to [B1: increase]/[B2: reduce] the population of disease-carrying rodents in the city by [B1: 250]/[B2: 300].

Change in City's Playground Capacity

[B1: Capacity for 250 MORE Children]/

[B2: Capacity for 225 FEWER Children]
Change in City's Disease-Carrying Rodent Population [B1: 250 MORE Disease-Carrying Rodents]/ [B2: 300 FEWER Disease-Carrying Rodents]

\section{[Combined Bill]}

The Municipal Legislature is considering the following bill. This bill has two parts:

PART A. [Exact text of Bill 1 from above].

PART B. [Exact text of Bill 2 from above].

\begin{tabular}{|l|l|l|}
\hline Bill & Change in City's Playground Capacity & Change in City's Disease-Carrying Rodent Population \\
\hline A & Capacity for 250 MORE Children & 250 MORE Disease-Carrying Rodents \\
\hline B & Capacity for 225 FEWER Children & 300 FEWER Disease-Carrying Rodents \\
\hline
\end{tabular}

